\title{
AC 2007-1229: ATTRACTING AND RETAINING WOMEN IN COMPUTER SCIENCE AND ENGINEERING: EVALUATING THE RESULTS
}

\section{David Keathly, University of North Texas}

David Keathly received the B.S. degree in Electrical Engineering (Computer Option) from Oklahoma State University in 1984 and the M.S. Degree in Electrical Engineering, also from OSU, in 1985. After 20 years of experience in developing military and commercial products, including a patent in image processing, as well as adjunct faculty assignments at Collin County Community College and the University of Texas at Dallas, he joined the faculty in Computer Science and Engineering at the University of North Texas as a Lecturer and Undergraduate Advisor in the Fall of 2004. He was an SGA Honors Professor in 2005 and is faculty advisor for the IEEE Computer Society, ACM and the UNT Programming Teams, in addition to his involvement with the recruiting and retention programs. David is also currently pursuing his $\mathrm{PhD}$ in Computer Science and is the co-director of both the RoboCamp program and the CSEagle Ambassador and Mentor program.

\section{Robert Akl, University of North Texas}

Robert Akl received the B.S. degree in computer science from Washington University in St. Louis, in 1994, and the B.S., M.S. and D.Sc. degrees in electrical engineering in 1994, 1996, and 2000, respectively. He also received the Dual Degree Engineering Outstanding Senior Award from Washington University in 1993. He is a senior member of IEEE. Dr. Akl is currently an Assistant Professor at the University of North Texas, Department of Computer Science and Engineering. In 2002, he was an Assistant Professor at the University of New Orleans, Department of Electrical and Computer Engineering. From October 2000 to December 2001, he was a senior systems engineer at Comspace Corporation, Coppell, TX.

\section{Ryan Garlick, University of North Texas}

Ryan Garlick received the B.B.A. degree in finance from the University of Texas in 1995. He received his M.S. and Ph.D. degrees in Computer Science from Texas State University and Southern Methodist University in 1998 and 2003, respectively. Since 2005, he has been a Visiting Assistant Professor in the Department of Computer Science and Engineering at The University of North Texas. Dr. Garlick also consults in the field of electronic commerce. 


\title{
Attracting and Retaining Women in Computer Science and Engineering: Evaluating the Results
}

\begin{abstract}
Computer science and engineering communities have been exploring a variety of activities and techniques to attract and retain more students, especially women and minorities, to computer science and computer engineering degree programs ${ }^{1}$. This paper briefly describes the efforts and results of a plan for actively recruiting young women into undergraduate computer engineering and computer science programs hosted by the University of North Texas (UNT). It also describes a series of activities aimed at improving the retention rate of students already in our programs, particularly during the freshman year. Such recruitment and retention efforts are critical to the country's efforts to increase the number of engineering professionals, and are a priority for the Computer Science and Engineering (CSE) Department at UNT.

We initially designed a three-part plan to achieve our recruitment and retention goals:

- Sponsorship of portable and mobile summer computer engineering robotics camps for middle and high-school women students, coordinating with the regional Girl Scouts councils and other organizations to help with the recruitment;

- Creation of an Ambassador program using young women currently enrolled in the upper division of current computer science and computer engineering programs as a form of outreach to area high schools and junior colleges; and

- Expansion of our successful undergraduate mentoring program by using the Ambassador cohort mentioned above as mentors for incoming freshman and first-year transfer women entering our programs.
\end{abstract}

This paper will focus primarily on the summer camp program and present an analysis of the results we have seen to date after 2 years of camp activities. Results from student surveys and parent surveys will be presented. The paper concludes with recommended changes and improvements in the program, as well as a discussion of adaptations that would create programs suitable for implementation at other institutions as well as programs aimed at a different target population.

The three phases previously enumerated each build upon currently accepted educational practices. The robotics summer camp in particular used problem-based learning approaches, similar to those described in The Power of Problem-Based Learning ${ }^{2}$. This study clearly demonstrates the significant benefits of teaching students how to think by using a problem-based approach. We also developed a mobile laboratory so that the summer camp can be held at several locations, thus broadening and expanding the reach of the camps to traditionally underserved populations and geographical regions. Similarly, both the ambassador and mentoring programs derive from research showing how the recruitment and retention of women in engineeringrelated fields can be increased by providing opportunities to develop student-to-student relationships ${ }^{3,4}$. 


\section{Strategy of Summer Robotics Camps}

Special summer camps for engineering students are a strategy that has been effective in promoting computer engineering among high school women ${ }^{5}$. Evidence exists that a curriculum developed around the programming of robots can attract new female students to computer science and engineering. As a result of this research, and our experience hosting the BEST Robotics competition, we conducted one-week Robotics Day Camps for young women entering the ninth, tenth and eleventh grades; one camp was offered at the North Texas Research Park in Denton and a second at a second UNT campus in south Dallas. The motivation for these camps was to increase the number of women selecting computer engineering as a field of study.

The Robotics Camps were organized around team, project-oriented activities that utilize a number of mobile resources, including laptops and the BOE-BOT (Board of Education Basic Stamp Microcontroller Carrier Board produced by Parallax - www.parallax.com ). The curriculum consisted of open-ended projects that produce observable behaviors and allow students to explore beyond the limits of defined exercises. Such activities included creatively programming the robots to draw different shapes and imagery - an unexpected activity initiated by a group of students during an open exploration period. The design of the project activities encouraged team exploration as well as independent operations. Working in a team environment encouraged the camp attendees to make individual contributions to the overall success of their efforts, regardless of whether their individual strengths lie in problem analysis, system design, construction or programming.

The camps' enrollment was limited to women in the ninth, tenth, and eleventh grades, although in the first year we had a small cadre of advanced eighth grade students join the camp. Evidence from the BEST Robotics events held at UNT in the Fall 2005 semester indicates that women are particularly attracted to educational and creative activities focused on robotics. For example, over one-third of the students who participated in the 2005 BEST competition were women. Anecdotal evidence from women attending this event, however, suggests that interaction among team members could be improved significantly if women-only teams were allowed to compete and work together. Several women complained that their male teammates often ignored their advice or suggestions. As a result of such remarks and other research ${ }^{6}$, we have decided to limit camp attendees to women only. The BEST program uses the local school environment to sponsor and support teams of students who come together for a single day competition. The Robocamp activities sought to bring young women from a number of different schools into a concentrated environment for an extended period that focuses more on collaboration than competition, as well as providing them with information to assist them in planning for their future education and career.

In order to ensure that there were sufficient numbers of women participating in the camps, we embarked on an aggressive recruitment plan. We used local media outlets, technology contacts in area school districts and direct mail to area middle schools and high schools. In addition, representatives from the Girl Scouts of the Cross Timbers Council (GSCTC) agreed to work with us in advertising and promoting the robotics camps. Currently, 172 ninth through eleventh grade women participate in the GSCTC, and GSCTC's overall recruitment efforts extend to all North Texas area schools with a potential audience of 11,000 women. A similar working relationship was established with the Tejas Council of the Girl Scouts to assist in recruiting students to attend the South Dallas Robocamp. Finally, we made presentations to the science and technology clubs 
and classes at area middle schools and high schools to encourage young women to participate in the program.

\section{Evaluation Structure}

The summer camp programs were designed to motivate student learning and improve recruiting by including creative problem-solving laboratory experiences, as well as higher education and career exploration and planning activities related to Science, Technology, Engineering and Math (STEM) disciplines. The project's overall goal was to develop summer camp programs that attract young women into science and engineering disciplines, as well as to implement strategies outside the scope of this paper to retain these students once they are in STEM disciplines.

The evaluation plan included both formative measures to provide feedback to project developers, and summative assessment to address project effectiveness. Formative evaluation strategies contribute to the development and implementation of the curriculum. Formative Evaluations were performed at the completion of the camps to answer these questions:

- How do students rate the quality of and their satisfaction with various activities?

- How do instructors, assistants and participants view the usefulness of their activities or participation?

The summative evaluation addressed the quality and usefulness of the completed activities. This data is collected at six month and one year offsets from the end of each camp. Summative evaluation questions included:

- What was the overall quality and effectiveness of the activities based on student and parent ratings and reviews?

- What impact did the camp activities have on the performance of the participants as they return to their secondary school, form both the student and parent perspectives?

- What impact did the camp activities have on the higher education and career plans of the participants?

- What were the demographic characteristics of students enrolled in each type of activity and how do they compare with demographic characteristics of students in the department as a whole?

\section{Specific Evaluation Results}

\section{General Trends}

Overall these programs coincided with a rise in our new student and continuing student populations as compared from Fall 2004 thru Fall 2006, as indicated in Table 1, as well as a concurrent rise in the number of students from underrepresented groups. The data in Table 1 represents the enrollment in all degree programs in the Computer Science and Engineering Department from 2004 to 2006, which corresponds with the period of our camp programs and related activities. The department has experienced slow but steady growth in the overall number of students (contrary to national trends), with significant growth in the number of women and 
minorities participating in our degree programs. We cannot, of course, attribute all of this growth uniquely to the summer camps, or even to the three new programs overall. However, the positive image created for UNT's College of Engineering and the CSE department has also had a positive impact on our enrollment numbers as evidenced by anecdotal evidence gathered from incoming students at orientation sessions conducted each semester by the investigators, who also serve as undergraduate advisors. We have experienced a number of positive indications specifically from incoming female and minority students who indicate that recent publicity regarding our targeted outreach programs created a favorable attitude personally and within their peer group towards attending UNT in STEM disciplines. We expect further improvement as we expand these efforts and we will continue to track the students who participate in the summer camps and mentoring activities, to determine their progress if already in a STEM degree program, or their eventual higher education choices as they move from high school into baccalaureate programs.

Table 1. Total Enrollment

\begin{tabular}{|c|c|c|c|c|}
\hline & Fall 2004 & Fall 2005 & Fall 2006 & Growth 04-06 \\
\hline Total Students & 697 & 755 & 761 & $9.34 \%$ \\
\hline Women & 77 & 93 & 124 & $61.04 \%$ \\
\hline Men & 620 & 662 & 637 & $2.74 \%$ \\
\hline African American & 65 & 85 & 91 & $40 \%$ \\
\hline Hispanic & 42 & 45 & 59 & $40.48 \%$ \\
\hline American Indian & 4 & 7 & 9 & $125 \%$ \\
\hline \% Women & $11.05 \%$ & $12.32 \%$ & $16.39 \%$ & ------------- \\
\hline$\%$ Minorities & $15.93 \%$ & $18.15 \%$ & $20.89 \%$ &  \\
\hline
\end{tabular}

\section{Summer Camp Attendance}

Focusing more closely on just the summer camp programs in 2005 and 2006, we see a clear diversity of ethnic backgrounds and grade levels represented in each program as indicated in Figure 1. Specifically we can see that a large number of minority students, particularly AfricanAmericans and Hispanics, have a strong interest in the program, particularly at the Dallas campus location which is situated in an area that is largely minority in population. We also note an increase in interest and awareness levels for the program (as judged by applications received) between the first and second year as a result of extensive press coverage both before and after the events. As an aid to publicity, the camps were included in a regional guide to summer camps published by the local newspapers, as well as appearing on the annual calendar for the local Girl Scout councils in the second year. In addition, the camp was the focus of a CNN local headline news story, a story by a local CBS affiliate, and a 20 minute segment prepared by our UNT Radio, Television and Film department that aired on local educational and public access television. Finally we appeared in several local and regional newspaper articles and numerous web-based news services utilized by the university. 
Ethnic Mix 2005 Camps

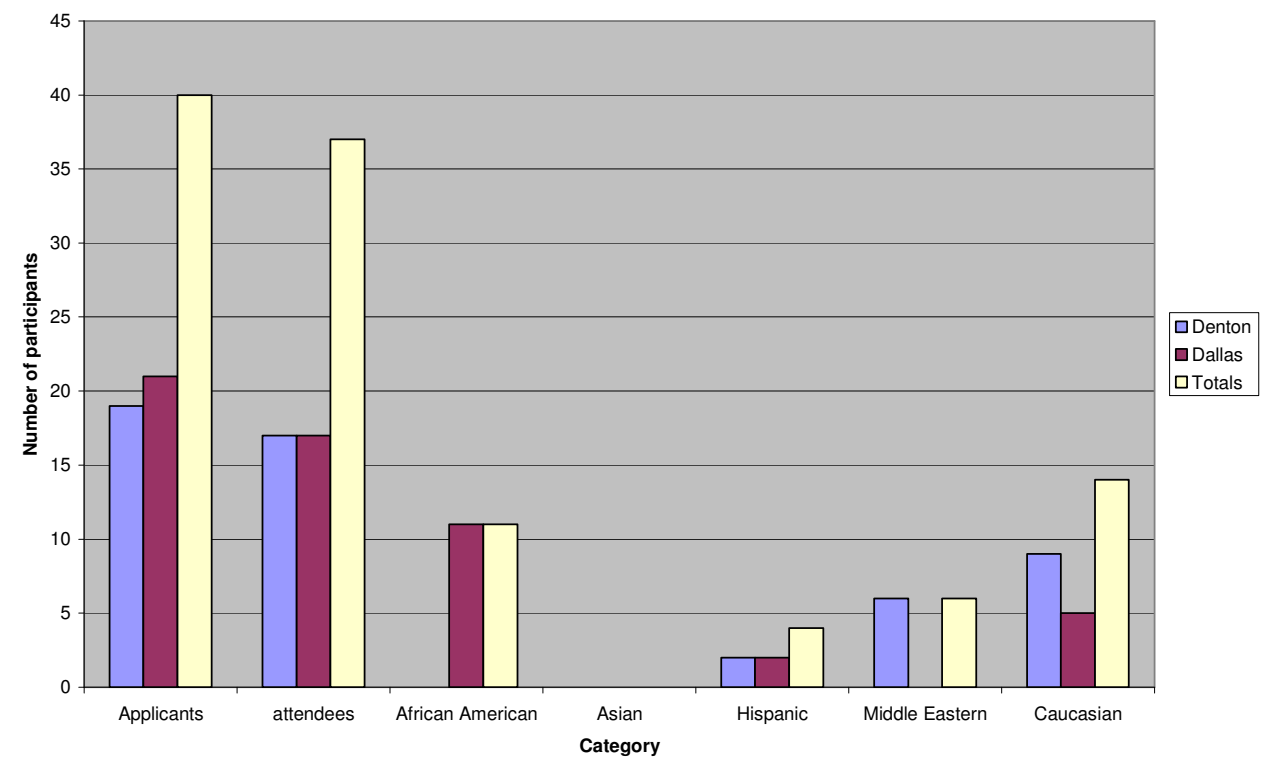

Ethnic Mix 2006 Camps

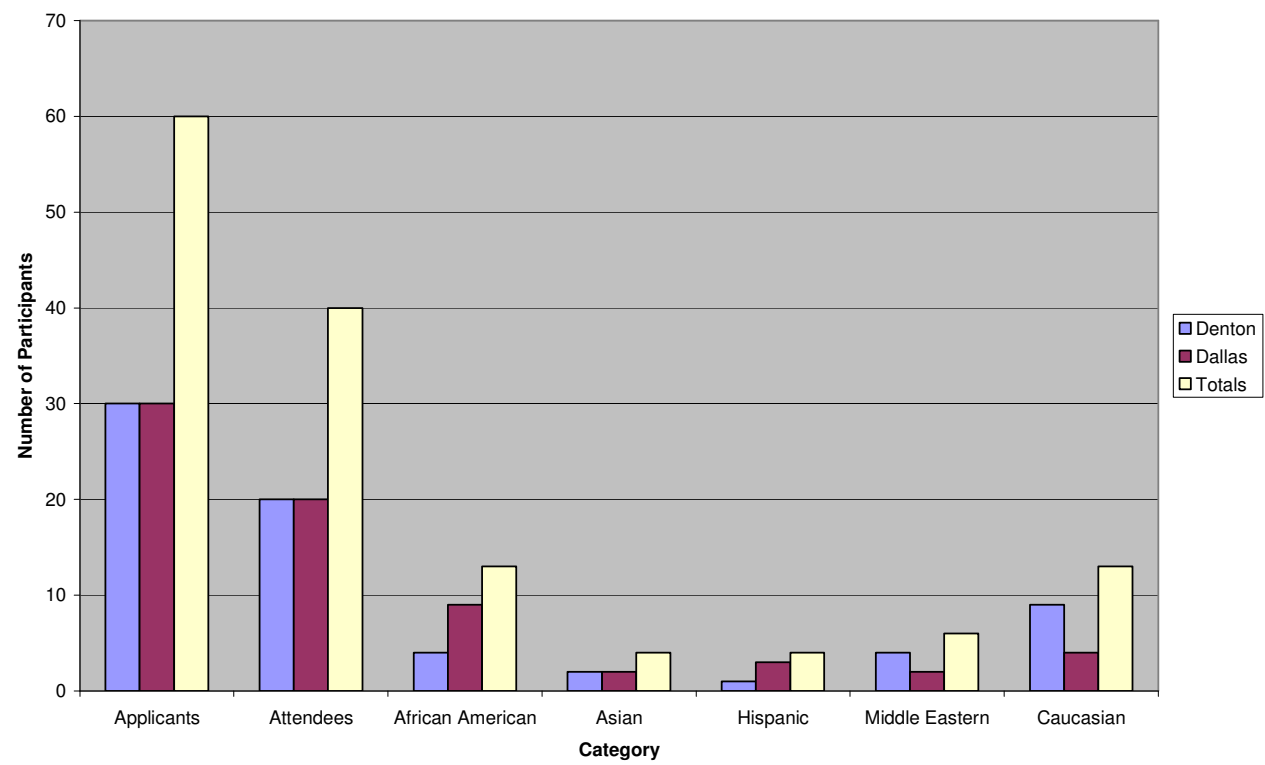

Figure 1. Ethnic Mix for Camps

Tables 2 and 3 highlight the grade distribution of students attending both camps. These show a steady migration of interest into later grade levels which we hope to sustain and generate a reversal of past trends among young women to move away from STEM-related interests as they move closer to high school graduation and are forced to choose between a number of competing activities and other interests on which to expend their interests, effort and energy. Although our focus has been on the $9^{\text {th }}$ to $11^{\text {th }}$ grades, we did have a small group of advanced $8^{\text {th }}$ graders who petitioned to attend the 2005 camp as a group and were admitted to the program. In future years 
we plan to expand the range of the camp into the middle school and even late elementary school levels.

Table 2. Robocamp 2005 Grade Distribution

\begin{tabular}{|c|c|c|c|c|c|c|} 
& $\mathbf{8}^{\text {th }}$ & \multicolumn{1}{|c|}{$\mathbf{9}^{\text {th }}$} & $\mathbf{1 0}^{\text {th }}$ & $\mathbf{1 1}^{\text {th }}$ & $\mathbf{1 2}^{\text {th }}$ \\
\hline Denton & 6 & 9 & 2 & & \\
\hline Dallas & 1 & 6 & 5 & 5 & \\
\hline Totals & $\mathbf{7}$ & $\mathbf{1 5}$ & $\mathbf{7}$ & $\mathbf{5}$ & \\
\hline
\end{tabular}

Table 3. Robocamp 2006 Grade Distribution

\begin{tabular}{|c|c|c|c|c|c|} 
& $\mathbf{8}^{\text {th }}$ & \multicolumn{2}{|c|}{$\mathbf{9}^{\text {th }}$} & \multicolumn{10}{c|}{$\mathbf{1 1}^{\text {th }}$} & $\mathbf{1 2}^{\text {th }}$ \\
\hline Denton & & 11 & 7 & 1 & $\mathbf{1}$ \\
\hline Dallas & & 10 & 7 & 3 & \\
\hline Totals & & $\mathbf{2 1}$ & $\mathbf{1 4}$ & $\mathbf{4}$ & $\mathbf{1}$ \\
\hline
\end{tabular}

\section{Summer Camp Exit Surveys}

Surveys conducted on the last day of each camp provide insight into the immediate results of the program. The charts in Figure $2 \mathrm{a}$ and $2 \mathrm{~b}$ illustrate the distribution of answers to selected questions from the exit surveys. (Note: questions not included in this list asked for information that was not in the form of a measurable answer such as "Where are you planning to attend college?") In particular the questions posed were:

* Q1 I feel that I learned something at RoboCamp 2006.

* Q2 The Robotics experiments were interesting, fun and educational.

* Q5 I would recommend this camp to my friends for next year.

* Q6 I would return to this camp another year.

* Q8 After this camp, I am considering a career in Math, Science or Engineering.

Exit Survey Results 2005

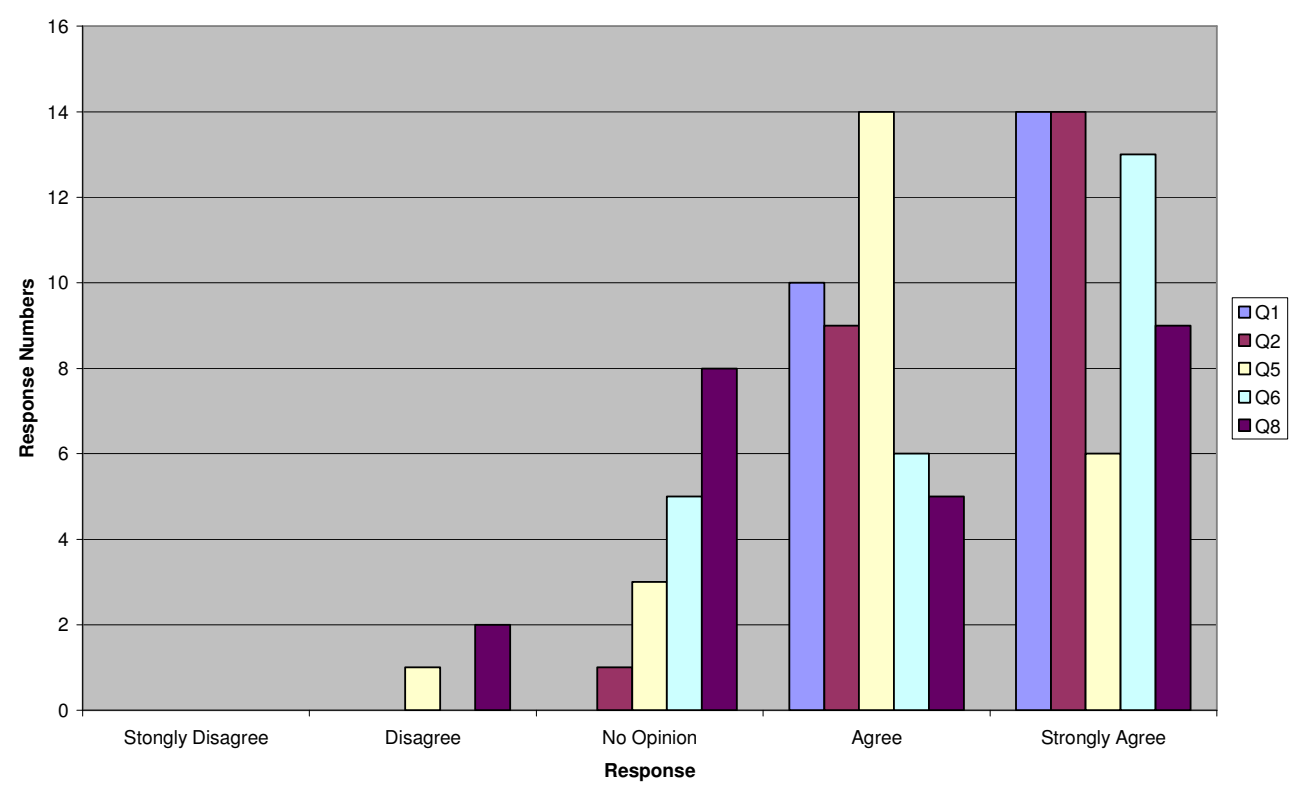

Figure 2a. Camp Exit Survey Results 2005 
Exit Surveys 2006

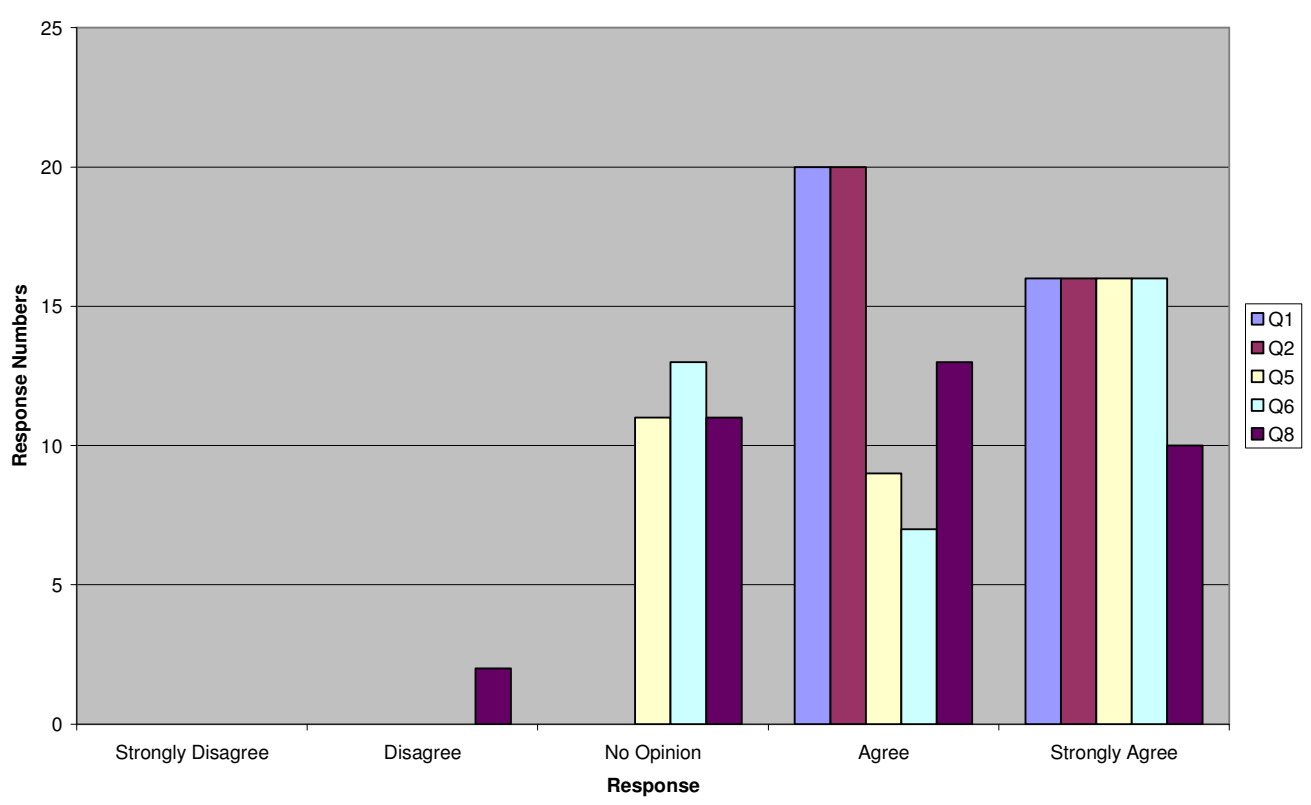

Figure 2b. Camp Exit Survey Results 2006

These results indicate an overall satisfaction with the learning experience and atmosphere provided by the camp, as well as a positive initial impact on the consideration of STEM-related educational objectives and careers by the participants. Overall there was very little negative response to any aspect of the camp, including the willingness to recommend the experience to peers.

\section{Summer Camp Follow-up Surveys}

Finally, the investigators conducted a post camp survey polling both parents and students to determine the long term educational and career plans for each participant, as well as the impact of their camp experience and interest in future activities of a similar nature. The results from the exit surveys are further reinforced by this data, which shows that camp experiences resulted in more deep-seated influence on school performance and interest after an "incubation" period of six months or more in which to absorb and reflect on the knowledge and skills obtained during Robocamp. Table 4 illustrates the student responses to selected questions on the post camp survey, and Table 5 indicates responses from the parent survey.

The student responses illustrated in Table 4 are based on the following questions:

1. Are you planning to attend college?

2. Did your experience at Robocamp affect your decision on a college and/or major?

3. Has your overall performance and interest in math and science improved as a result of your experiences at Robocamp?

4. Would you be interested in an advanced level Robocamp if one were offered?

5. If a scholarship were available for Robocamp graduates to attend UNT in math, science or engineering would you be interested? 
The parent responses illustrated in Table 5 are based on the following questions:

1. Is your daughter planning to attend college?

2. Does your daughter have a strong interest in math, science or engineering topics?

3. Has her overall performance and interest in math and science improved as a result of her experiences at Robocamp?

4. Would your daughter be interested in an advanced level Robocamp if one were offered?

5. If a scholarship were available for Robocamp graduates to attend UNT in math, science or engineering would your daughter be interested?

6. Do you feel that the Robocamp experience had any other positive or negative impacts on your daughter's performance at school or otherwise?

Table 4. Student Post Camp Survey (\% of respondents)

\begin{tabular}{|c|c|c|c|}
\hline Question & Yes & No & Undecided \\
\hline 1 & $100 \%$ & & \\
\hline 2 & $50 \%$ & $30 \%$ & $20 \%$ \\
\hline 3 & $82 \%$ & $18 \%$ & \\
\hline 4 & $90 \%$ & $10 \%$ & \\
\hline 5 & $90 \%$ & $10 \%$ & \\
\hline
\end{tabular}

Table 5. Parent Post Camp Survey (\% of respondents)

\begin{tabular}{|c|c|c|c|}
\hline Question & Yes & No & Undecided \\
\hline 1 & $100 \%$ & & \\
\hline 2 & $73 \%$ & $27 \%$ & \\
\hline 3 & $60 \%$ & $33 \%$ & $7 \%$ \\
\hline 4 & $73 \%$ & $7 \%$ & $20 \%$ \\
\hline 5 & $71 \%$ & & $29 \%$ \\
\hline 6 & $100 \%$ & & \\
\hline
\end{tabular}

These results indicate that the Robocamp experience was very positive as viewed by both the parents and the students, and that the activities enhanced not only interest in math and science, but also performance in these subjects upon returning to school. Many students have now considered altering their initial thoughts about academic programs and careers to give serious attention to STEM disciplines as a result of their camp experiences.

Anecdotal Comments from Surveys

This section provides a few quotes from the post camp surveys of both the students and the parents.

"It opened my mind to considering this as a career" - Student Q2

"Yes, I understand more, and I am even taking a course in robotics, now. I'm actually passing." Student Q3

"Yes it affected what I wanted to major in. I wanted to first major in business, now I want to major in computers" - Student Q2

"Yes, right now I take Chemistry and Algebra II/Trigonometry. In Chemistry, I have a 95. In Algebra II, I have a 93.” - Student Q3

"Yes I have been much more interested in science since Robocamp" Student Q3 
"I had already known I was interested in math and science, however, my experience at Robocamp further enforced my decision. It also made me think that engineering would be an ideal field to study" - Student Q2

"Most definitely. My high school requires us to take one credit of computer science and this camp helped me choose which course to take. I am also more aware of what people are talking about when they discuss robotics. Robocamp further strengthened my interest in math and science" - Student Q3

"As I mentioned previously, I think the program gave her additional confidence, particularly because it was an all-girls class. Besides being female, she is also quite naturally introverted, so activities like this do help a great deal. I think it has given her confidence and a sense of direction. She is much more likely to discuss her experience at Robocamp and relate it to other things she is doing, whether in school or in extracurricular activities. I recommend the program to everyone I can think of with a daughter who might be interested in science" - Parent Q6

"Yes, her grades improved greatly in math and science" - Parent Q3

"She now tries to think thru the problems rather than just solve them" - Parent Q6

"She, as of right now, is planning on going to college. No college has been chosen but she is interested in engineering (because of last year's camp!!)" - Parent Q1

"Math was never an easy subject for her, but since last year's camp, she has been determined to learn all the math she can. She has completed her Pre-Algebra textbook on her own in the past six months. She is EAGER to start Algebra." Parent Q3

"In the past, Sam always felt like math and science were for 'smart kids' and that it had to be boring. Camp changed some of these stereotypes for her. Now that she does not see these subjects as an opportunity to fail, she is better able to focus her efforts and succeed." - Parent Q6

"Yes. This year she has A/B's in math and science. We believe that she finally figured out that she CAN do it so as a result she listens and tries harder" - Parent Q3

"Great job! Thanks for bringing highly intelligent individuals to this project that were still able to communicate on a real level with these kids (That was a big concern for me when I initially enrolled my daughter.)" - Parent additional comments

\section{Discussion and Summary}

The results obtained to date indicate that the RoboCamp summer program has resulted in increased interest in STEM related educational objectives and careers among the participants, as well as generating a positive image for the Computer Science and Engineering programs in the surrounding community. In turn, this image enhancement has contributed to the overall growth in recruiting and retention results observed in the period from 2004 to 2006.

The post camp surveys and, in particular, the comments provided by the students and their parents beyond the simple yes or no answers provides some of the most compelling evidence for the efficacy of this type of program. So many of the students found a renewed interest in math and science, perhaps reinforcing natural tendencies that were subverted by peer pressure and societal stereotypes, as well as actually improving their immediate performance in math and science courses as a result of this renewed interest. They indicated a bolstered level of 
confidence in their abilities in STEM-related subjects and a sense of belonging to an everwidening community of women pursuing education and careers in STEM fields.

\section{Information for Potential Adopters}

The authors have created websites for each camp year, as well as for our ambassador and mentor programs with information about the programs, photos, music videos and other relevant information. In addition, the authors can make available individual presentations, laboratory assignments, equipment details and other information to those who would like the offer a similar program at their institution. Please contact us at (940) 565-2767 or via email at dkeathly@ cse.unt.edu,$\underline{\text { rakl@ cse.unt.edu }}$ or garlick@ cse.unt.edu .

\section{Acknowledgements}

This work was supported in part by the Texas Technology Workforce Development Grant Program (2005) Recruiting and Retention Strategies for Computer Science and Engineering at UNT no. 003594-CS2005-1000. The authors would like to thank all young women and students assistants that participated in RoboCamp, as well as the mentoring and ambassador programs.

\section{References}

1. Anderson-Roland, M. and Cosgrove, C. Factors that engineering students consider. Annual Convergence Proceedings, American Society for Engineering Education, Anaheim, Calif., 1995, pp. 1027-1031.

2. Duch, B. J., Groh, S.E., and Allen, D.E. The Power of Problem-Based Learning. Stylus Publishing, Sterling VA, 2001.

3. Astin, A. What matters in college: Four critical years revisited. Jossey-Bass: San Francisco, 1993.

4. Felder, R., Woods, D., Stice, J. and Rugarda, A. The future of engineering education II: teaching methods that work. Chem. Engr. Education, vol. 34, no. 1, 2001, pp. 26-39.

5. McKeachie, W. J., Pintrich, P.R., Lin, Y. and Smith, D.F.A. Teaching and Learning in the College Classroom: A Review of the Research Literature. ED340272 Sep 91 Active Learning: Creating Excitement in the Classroom. ERIC Digest, 1986.

6. Pollock, L., McCoy, K., Carberry, S., Hundigopal, N., and You, X. "Increasing high school girls' self confidence and awareness of CS through a positive summer experience," Proceedings of the Special Interest Group on Computer Science Education, 2004. 